\title{
A Comparison of the Activity and Disposal of Semi-Synthetic Human Insulin and Porcine Insulin in Normal Man by the Glucose Clamp Technique
}

\author{
P.D. Home, M. Massi-Benedetti, G. A. A. Shepherd, I. Hanning, K. G. M. M. Alberti and D. R. Owens \\ Department of Clinical Biochemistry and Metabolic Medicine, University of Newcastle upon Tyne, UK
}

Summary. The activity of semi-synthetic human insulin has been compared with porcine insulin in normal man using an euglycaemic glucose clamp at two different insulin infusion rates. In a two hour infusion insulin levels plateaued for both types of insulin at $44-48 \mathrm{mU} / 1$ (infusion rate $0.05 \mathrm{U} \mathrm{kg}$ body weight $^{-1}$ $\left.\mathrm{h}^{-1}\right)$ and $22-24 \mathrm{mU} / 1\left(0.02 \mathrm{U} \mathrm{kg}^{-1} \mathrm{~h}^{-1}\right)$, giving identical metabolic clearance rates. The glucose delivery required to maintain euglycaemia in the second hour of insulin infusion was $13.9 \pm 2.1 \mathrm{~g}$ (mean \pm SEM) and $14.7 \pm 1.5 \mathrm{~g}(\mathrm{NS})$ at the lower dose for porcine and human insulins respectively, and $27.1 \pm 2.5$ and $28.0 \pm 2.9 \mathrm{~g}$ (NS) at the higher dose. The potency ratio for human, compared with porcine, insulin was 1.06 \pm 0.12 . No differences were seen in the time of onset of action of the insulins, serum half-life or distribution space. The responses of blood lactate, pyruvate, alanine, glycerol and 3-hydroxybutyrate were identical. No untoward reactions occurred. The activity and disposal of this semi-synthetic human insulin are indistinguishable from porcine insulin in normal euglycaemic man.

Key words: Human insulin, insulin activity, insulin pharmacokinetics, glucose clamp.

Human insulin differs from porcine and bovine insulin by one and three amino acids respectively. Human insulin prepared by total synthesis [1] has been shown to be active in diabetics [2], while that produced by recombinant DNA technology has a similar hypoglycaemic effect to porcine insulin in normal man [3]. Semi-synthetic human insulin, prepared by chemical substitution of the B30 alanine or porcine insulin with threonine $[4,5]$ is now available for clinical trials. In normal fasting subjects it has been found to have equivalent effects to porcine insulin on plasma glucose and intermediary metabolites [6].
All the above studies used protocols in which hypoglycaemia was induced. This complicates quantitative comparison of the activities of human and other insulins due to secretion of counter-regulatory hormones in response to the hypoglycaemia. We have therefore measured the activity of semi-synthetic human insulin in the euglycaemic state by the glucose clamp technique $[7,8]$, using a blood glucose controlled glucose infusion system. The glucose infused to maintain euglycaemia is then a measure of insulin activity. Human and porcine insulin were infused at two doses in normal man using a parallel line doseresponse bioassay, which allows an estimate of the relative potency of human insulin. C-peptide levels were measured to ensure that endogenous insulin secretion did not differ significantly during the exogenous insulin infusion. Insulin activity was further assessed by examining the intermediary metabolite response to insulin infusion, and the pharmacokinetic properties of insulin were also measured.

\section{Subjects and Methods}

\section{Subjects}

Six healthy male volunteers consented to take part in the study. Permission for the study was also obtained from the Newcastle upon Tyne Area Health Authority (Teaching) Ethical Committee. All subjects were within $10 \%$ ideal body weight [9], with a mean weight of $69.9 \pm 0.8 \mathrm{~kg}$ ( $\pm \mathrm{SD}$ ). Their age range was $22-43$ years. They were asked to maintain their normal diet for three days before each study, and to fast from midnight on the evening beforehand. No subject was known to be suffering from any disease and none were taking drugs of any kind.

\section{Insulins}

Each subject was studied on four separate occasions, with IV infusion of highly purified porcine (Actrapid, Novo) and semi-synthetic human insulins, at a high $\left(0.05 \mathrm{U} \mathrm{kg}\right.$ body weight $\left.{ }^{-1} \mathrm{~h}^{-1}\right)$ and low $\left(0.02 \mathrm{U} \mathrm{kg}^{-1} \mathrm{~h}^{-1}\right)$ dose. The order of administration was randomised. Semi-synthetic human insulin (kindly provided by Novo In- 

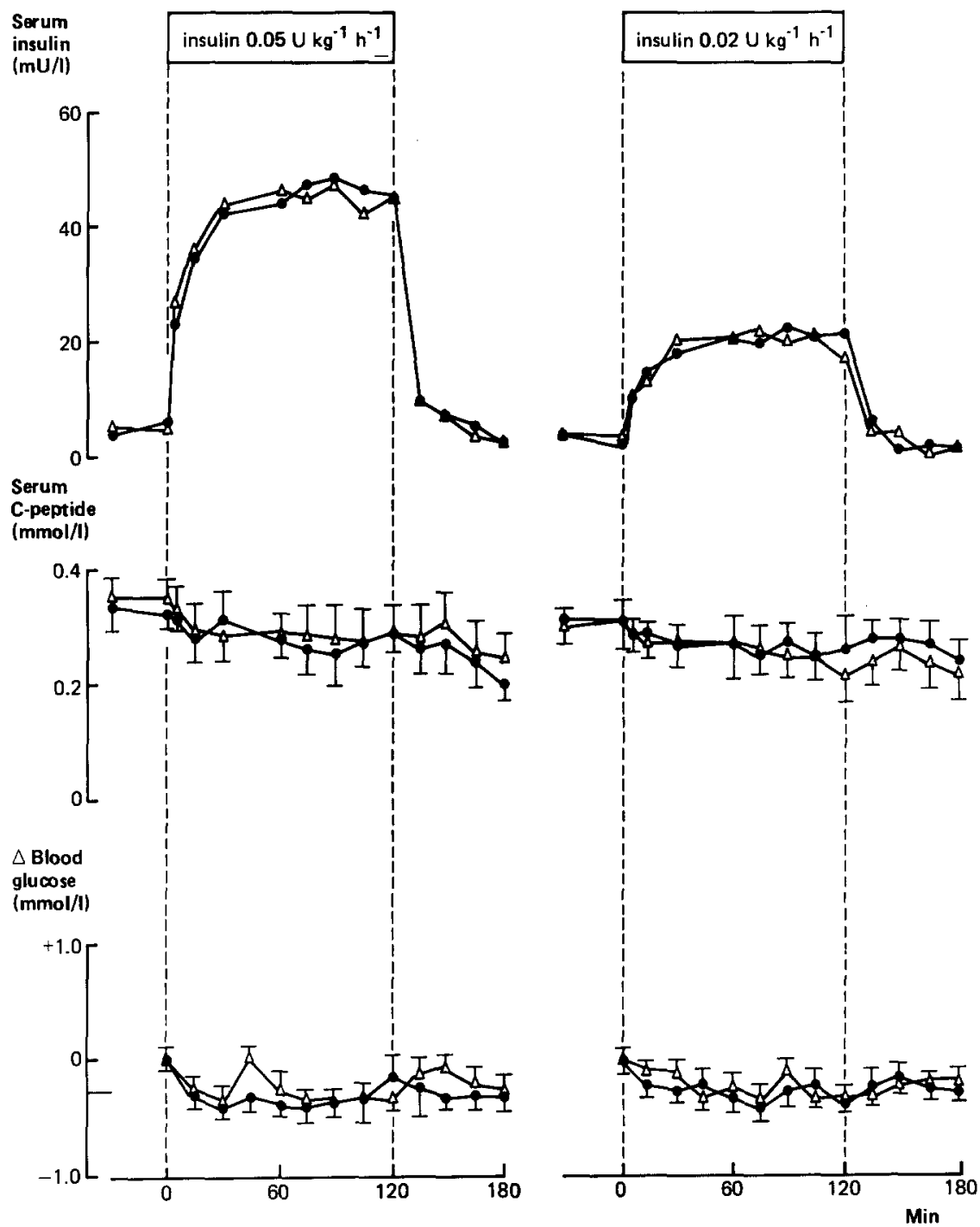

Fig. 1. Serum insulin and C-peptide levels, and change in blood glucose concentrations during and after infusion of human $(-)$ and porcine $\left(\Delta-\Delta\right.$ ) insulins at $0.05 \mathrm{U} \mathrm{kg}^{-1} \mathrm{~h}^{-1}$ (left) and $0.02 \mathrm{U} \mathrm{kg}^{-1} \mathrm{~h}^{-1}$ (right). Insulin was infused IV from 0 to $120 \mathrm{~min}$. Blood glucose was maintained by feedback glucose infusion programmed to keep the subject's blood glucose concentration $0.28 \mathrm{mmol} / 1$ below fasting levels. On the lowest graphs the change in blood glucose is taken from $0 \mathrm{~min}$, and the intended level of the clamp is indicated by the short horizontal line. Error bars are mean $\pm S E M$. For insulin the mean SEM in the second hour was $2.5 \mathrm{mU} / 1$

dustri, Copenhagen) derived from porcine insulin by enzymatic substitution of the B terminal alanine with threonine, and purified to monocomponent specification, was prepared to be equimolar with the Actrapid. On each occasion the required total dose was diluted to $30 \mathrm{ml}$ with Haemaccel (Hoechst) on the day of infusion.

\section{Protocol}

On the morning of the study three polytetrafluoroethylene cannulae were inserted IV into each subject. One cannula, in an antecubital fossa, was used for intermittent blood sampling, being flushed after use with $0.5 \mathrm{ml} 0.15 \mathrm{~mol} / 1$ saline. A second, distally on the same arm, was used as a double lumen cannula for continuous sampling by a blood glucose controlled glucose infusion system (Biostator, Miles, Frankfurt). The third, on the other arm, was used for all infusions. A period of one hour was allowed for equilibration, calibration of the instrument and achieving stability of the glucose sensor response.

At the end of calibration (time $0 \mathrm{~min}$ ) the insulin infusion was begun. The Biostator constants were initially set to cause very little glucose infusion $(\mathrm{QD}=5, \mathrm{RD}=50)$ until the blood glucose fell to $0.28 \mathrm{mmol} / \mathrm{l}$ below its fasting level, and then adjusted to maintain a glucose clamp around this new level. The QD was then kept at 20. An additional infusion of glucose $(85 \mathrm{mg} / \mathrm{min}$ at the low insulin dose, $170 \mathrm{mg} / \mathrm{min}$ at the high dose) was added throughout the period of the clamp. The insulin infusion continued for $120 \mathrm{~min}$, and the glucose clamp for a further $60 \mathrm{~min}$. Blood samples were taken at $-30,0,15,30$ and $60 \mathrm{~min}$, then every $15 \mathrm{~min}$ until $180 \mathrm{~min}$. Blood for metabolite assay was immediately deproteinized in perchloric acid $0.5 \mathrm{~mol} / 1$, and the extract stored at $4{ }^{\circ} \mathrm{C}$ until analysis within $24 \mathrm{~h}$. Lactate, pyruvate, glycerol, alanine and 3-hydroxybutyrate were estimated by standard fluorimetric methods [10]. Serum insulin was measured by double antibody radioimmunoasay [11] (sensitivity $1 \mathrm{mU} / \mathrm{l}$; intra-assay coefficient of variation $7 \%$ ) using human insulin as standard. The antibody used (Wellcome) had 100\% cross reactivity with porcine compared with human insulin. Serum Cpeptide was measured by radioimmunoassay with ethanol precipitation [12] (sensitivity $0.02 \mathrm{nmol} / 1$, intra-assay coefficient of variation 3\%). Additional blood samples were taken from 120 to $135 \mathrm{~min}$ at 3 min intervals after cessation of the high dose infusion, for estimation of insulin half-life in vivo. 


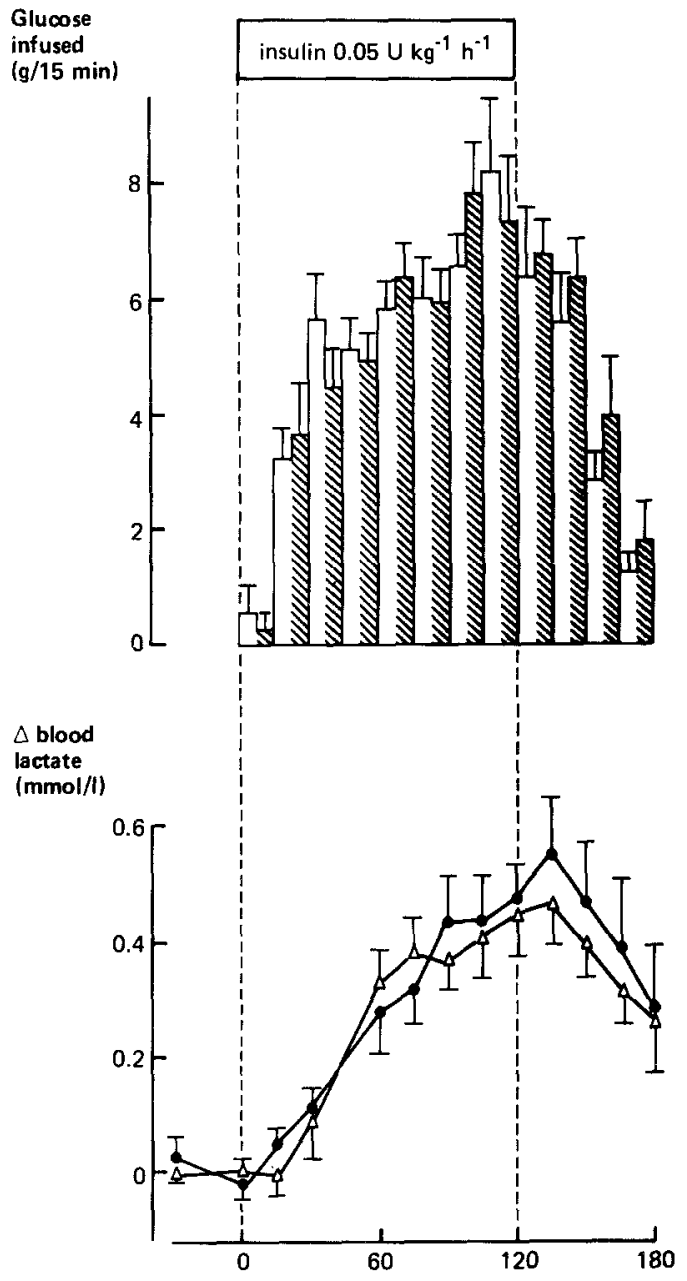

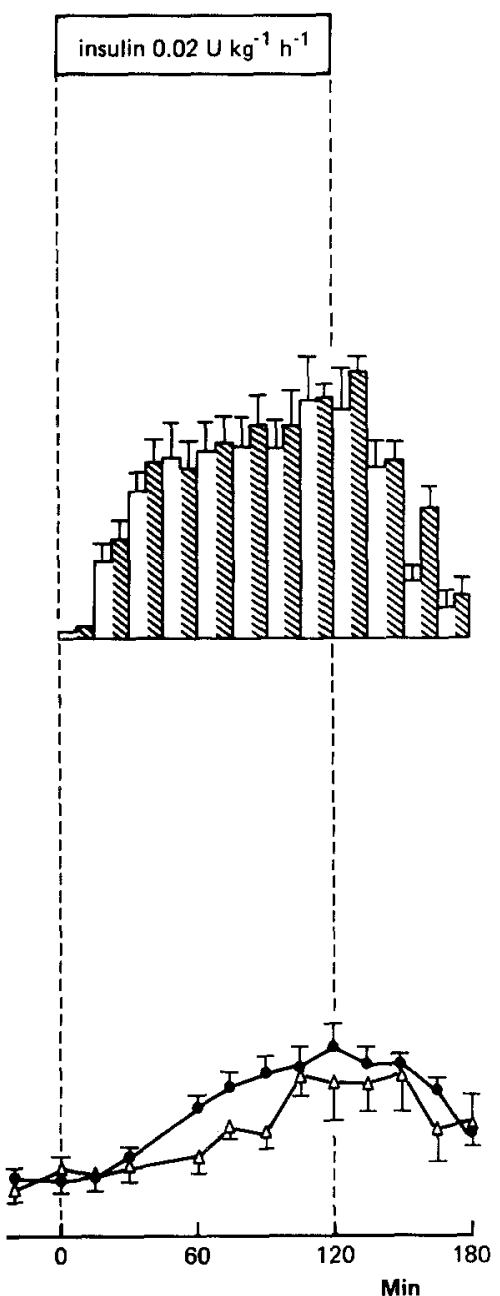

Fig. 2. Glucose requirements for the maintenance of euglycaemia and blood lactate responses during and after infusion of porcine and human insulin at 0.05 and $0.02 \mathrm{U} \mathrm{kg}^{-1} \mathrm{~h}^{-1}$. Insulin was infused from 0 to $120 \mathrm{~min}$. On the upper figure each histogram is the mean \pm SEM of glucose infused over $15 \min (n=6)$. The left hand (clear) half of each histogram represents porcine insulin, and the right hand (hatched) human insulin. On the lower figure $\Delta=$ lactate response to porcine insulin and $\mathbf{0}=$ human insulin. The absolute fasting values for lactate are given in Table 1

\section{Statistics}

Results were analysed by standard parametric methods and are stated as mean \pm SEM unless otherwise indicated. Analysis of variance and Students's paired ' $t$ ' test were used as appropriate. Insulin sensitivity was calculated as the amount of glucose infused to maintain the euglycaemia in the second hour of insulin infusion, when the glucose infusion rate was relatively constant. The potency ratio was calculated by standard equations for $2+2$ parallel line bioassays, and the significance of differences and the error estimated by analysis of variance and simplifications of Fieller's theorem [13]. Metabolic clearance rate [14] and distribution space [15] were estimated by standard equations. Insulin half-life was calculated by fitting mono-exponential curves to the results for each subject. The contribution of endogenous insulin secretion was accounted for by subtracting the basal insulin level, but allowing for the suppression of pancreatic insulin secretion as measured by the fall in C-peptide concentrations.

\section{Results}

Serum insulin levels were indistinguishable after infusion of human and porcine insulins (Fig. 1), plateauing at around $46 \mathrm{mU} / 1$ (high dose) and $22 \mathrm{mU} / 1$ (low dose). Allowing for endogenous insulin secretion, metabolic clearance rates were $1.42 \pm 0.04$ and $1.33 \pm 0.101 / \mathrm{min}$ for porcine and human insulin respectively at the high dose (NS) and $1.27 \pm 0.08$ and $1.25 \pm 0.11 \mathrm{l} / \mathrm{min}$ at the low dose (NS). Slight suppression of endogenous insulin secretion as reflected by C-peptide levels was found with both insulins, with no significant difference between them. Serum insulin levels decayed monoexponentially between 3 and 12 min after cessation of the insulin infusion $(r=0.97, p<0.001)$. Over this time the serum half life in vivo of porcine insulin was $5.1 \pm 0.9 \mathrm{~min}$ and for human insulin $4.6 \pm 0.5 \mathrm{~min}$ (NS). The distribution space was $12.6 \pm 2.71$ for porcine and $10.1 \pm 1.91$ for human insulin (NS) when infused at $0.05 \mathrm{U} \mathrm{kg}^{-1} \mathrm{~h}^{-1}$.

Blood glucose levels were maintained at satisfactory levels using the Biostator with a mean deviation from the intended concentration of $0.05 \mathrm{mmol} / \mathrm{l}$ in the second hour. The coefficient of variation of blood glucose values in each subject for the period of the clamp was $5.9 \pm 0.5 \%$. 
Table 1. Blood intermediatry metabolite levels before and at the end of $2-\mathrm{h}$ infusions of porcine insulin $\left(0.02\right.$ and $\left.0.05 \mathrm{U} \mathrm{kg}^{-1} \mathrm{~h}^{-1}\right)$ and equimolar amounts of semi-synthetic human insulin. Euglycaemia was maintained by a glucose clamp.

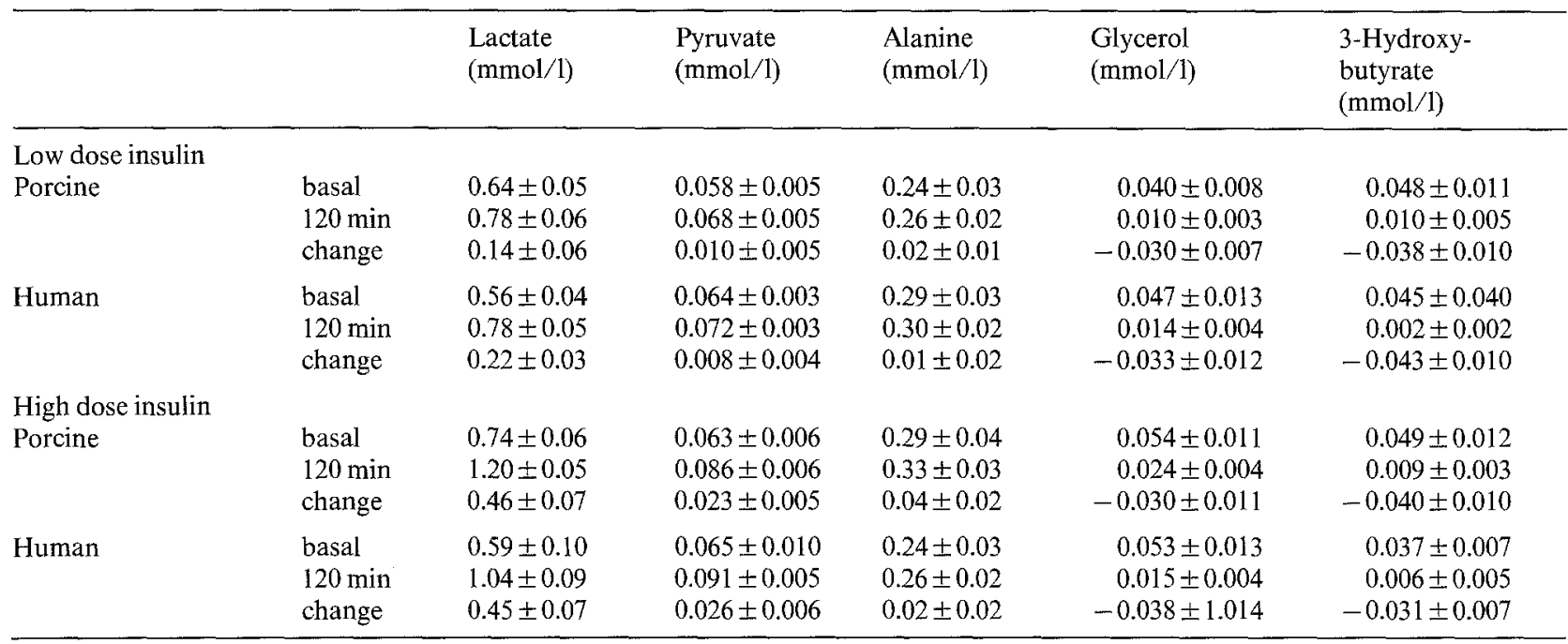

Results are mean $\pm \mathrm{SEM}$

For porcine and human insulins respectively the time taken for the blood glucose to drop $0.28 \mathrm{mmol} / 1$ from the start of the insulin infusion was $19 \pm 4$ and $17 \pm 2 \min$ (low dose, NS) and $15 \pm 1$ and $16 \pm 1 \mathrm{~min}$ (high dose, NS).

Feedback glucose infusion increased throughout the $2 \mathrm{~h}$ of insulin infusion, and declined only slowly thereafter (Fig. 2). No significant difference was detected in the glucose required to maintain the clamp in any 15-min period during the study. At the low dose, glucose requirements for the second hour were $13.9 \pm 2.1 \mathrm{~g}$ for porcine insulin and $14.7 \pm 1.5 \mathrm{~g}$ for human insulin (NS). At the high dose these figures were $27.1 \pm 2.5$ and $28.0 \pm 2.9 \mathrm{~g}$ respectively (NS). Part of the error is accounted for by a significant difference in insulin sensitivity between subjects $(F=$ $5.09, p<0.01$ ). The overall potency ratio of human insulin expressed as a fraction of porcine insulin was $1.06 \pm 0.12$.

The alanine, glycerol and 3-hydroxybutyrate responses to the two insulins were similar (Table 1). There was also no difference in the effect on these metabolites at the two different insulin doses. With lactate (Fig. 2) and pyruvate (Table 1), however, there was a significantly greater response $(p<0.01$ in the second hour) to the higher insulin dose, but there were no significant differences in the effects of the two insulins.

\section{Discussion}

Glucose clamp techniques allow comparisons of the activity of insulins at a steady blood glucose concentration $[7,8]$, and thus without the interference of counter-regulatory responses to hypoglycaemia. Glucose delivery is then proportioned to insulin activity. Massi-Benedetti et al. [16] have compared biosynthetic human and pancreatic porcine insulins this way, without finding significant differences. Their use of sequentially rising insulin doses on the same day obviates, however, comparisons of insulin activity at different dose levels, and imposes problems of calibration drift when the glucose feedback system is in continuous operation. More sophisticated analysis of their results was not therefore possible. In the current study the artificial pancreas (Biostator) was used to obtain successful glucose clamps (Fig. 1) with peripheral insulin levels in the upper and lower regions found for free-insulin in insulin treated diabetics [17]. The 20\% suppression of serum C-peptide (Fig. 1) confirms a stable contribution of endogenous insulin, at sub-fasting levels.

Glucose delivery during the $2 \mathrm{~h}$ insulin infusion failed to reveal any difference in activity between semi-synthetic human and porcine insulins. The data on glucose delivery in the relatively stable second hour fulfil the assumptions of regression between the two dose levels $(F=62.5, p<0.001)$ and lack of deviation from parallelism ( $F=0.00$, NS) between the two insulins. Linearity is not assessable in a $2+2$ bioassay, but the results of Massi-Benedetti et al. [16] suggest a linear dose-response relationship at these infusion rates. On this basis the potency of human insulin in normal man is indistinguishable from equi-molar porcine insulin (potency ratio $1.06 \pm 0.12$ ).

The time of onset of action of the insulins was also identical. No differences could be detected in distribution space, metabolic clearance rate, or serum half- 
life. These estimates were not significantly different from previously published results for exogenous human insulin $[18,19]$.

Lipolysis and ketogenesis were rapidly suppressed by even the lower of the insulin doses, and hence this study is a very insensitive way of detecting differences between the two insulins in repect of glycerol and ketone body responses. Similarly alanine levels were identical at the two doses, the lack of change presumably reflecting a balance of hepatic and peripheral effects of the insulins. In contrast the increase in lactate and pyruvate levels was significantly different between the two doses but similar with the two insulins.

Semi-synthetic human insulin is thus similar in many aspects of its activity to porcine insulin in subjects expected to be free of insulin antibodies. No adverse reaction has been reported in this or our previous study [6]. Preliminary studies in diabetics suggest no detectable differences in activity when compared with monocomponent porcine and bovine, or standard soluble bovine, insulins [20]. The benefits of this new insulin now need to be explored in insulin-treated diabetics using properly structured double blind trials.

Acknowledgements. We are very grateful for the support of Novo Laboratories and the British Diabetic Association.

\section{References}

1. Sieber P, Kamber B, Hortmann A, Jöh1 A, Riniker B, Rittel W (1974) Totale Synthese von Humaninsulin Gezielter Bildung der Disulfidbindungen. Helv Chim Acta 57: 2617-2621.

2. Teuscher A (1979) Die biologische Wirkung von vollsynthetischen humanen Insulin bei Patienten mit Diabetes mellitus. Schweiz Med Wochenschr 109: 743-747.

3. Keen H, Glynne A, Pickup JC, Viberti GC, Bilous RW, Jarrett RJ, Marsden R (1980) Human insulin produced by recombinant DNA technology: safety and hypoglycaemic potency in healthy man. Lancet 2: 398-401.

4. Marihara K, Oka T, Tsuzuki H(1979) Semi-synthesis of human insulin by trypsin-catalyzed replacement of Ala-B30 by Thr in porcine insulin. Nature $280: 412-413$.

5. Gattner H-G, Danho W, Naithani, VK (1981) Enzyme-catalysed semi-synthesis with insulin derivatives. In: Brandenburg D, Wollmer A (eds) Insulin chemistry, structure and function of insulin and related hormones. Proceedings of the second international insulin symposium, Aachen, Germany, September 1979. Walter de Gruyter, Berlin, pp 117-123
6. Owens DR, Jones MK, Hayes TM, Heding LG, Alberti KGMM, Home PD, Burrin JM, Newcombe RG (1981) Human insulin: a study of safety and efficacy in normal man. Br Med J 282: $1264-1266$

7. Alberti KGMM, Nosadini R, Noy GA, Kurtz AB (1979) Differential response of insulin-dependent diabetics to infusions of bovine and highly purified porcine insulins: a preliminary report. Adv Exp Med Biol 119:329--335

8. De Fronzo RA, Tobin JD, Andres R(1979) Glucose clamp technique: A method for quantifying insulin secretion and resistance. Am J Physiol 237: 214-223

9. Desirable weights of adults. In: Diem K (ed) Documenta Geigy, 6th edn. Geigy (UK) Ltd, Macclesfield, p 624

10. Lloyed B, Burrin JM, Smythe P, Albert KGMM (1978) Enzymatic fluorimetric continuous-flow assays for blood glucose, lactate, pyruvate, alanine, glycerol and 3-hydroxybutyrate. Clin Chem 24: 1724-1729

11. Hales CN, Randle PJ (1963) Immunoassay of insulin with insulin-antibody precipitate. Biochem J 88 : 137-146

12. Heding LG (1975) Radioimmunological determination of human C-peptide in serum. Diabetologia 11:541-548

13. Colquhoun D (1971) Lectures in biostatics. Clarendon Press, Oxford, pp 279-343

14. Tait JF (1963) The use of isotopic steroids for the measurement of production rates in vivo. J Clin Endocrinol 23: 1285-1297

15. Zilversmidt DB (1960) Design and analysis of isotopic experiments. Am J Med 29: 832-848

16. Massi-Benedetti M, Burrin JM, Capaldo B, Alberti KGMM (1981) A comparative study of the activity of E coli-derived human insulin and porcine insulin using the glucose clamp technique in normal man. Diabetes Care 4: 163-167

17. Rizza BA, Gerich JE, Haymond MH, Hall LD, Clemens AH, Service FJ (1980) Control of blood sugar in insulin-dependent diabetes: Comparison of an artificial endocrine pancreas, continuous subcutaneous insulin infusion, and intensified conventional insulin therapy. N Engl J Med 303: 1313-1318

18. Turner RC, Grayburn JA, Newman GB, Nabarro JDN (1971) Measurement of the insulin delivery rate in man. J Clin Endocrinol Metab 33: 279-286

19. Sönksen PH, Tompkins CV, Srivastava MC, Nabarro JDN (1973) A comparative study on the metabolism of human insulin and porcine proinsulin in man. Clin Sci Mol Med 45: 633-654

20. Shepherd GAA, Home PD, Noy G, Hanning I (1981) A comparison of the activity of insulins from different species injected subcutaneously in insulin-dependent diabetics (IDD) using the glucose clamp technique. Diabetologia $21: 327$ (Abstract)

Received: 15 May 1981

and in revised form: 27 July 1981

Dr. Philip Home

Department of Clinical Biochemistry and Metabolic Medicine

Royal Victoria Infirmary

Newcastle upon Tyne NE1 4LP, UK 